\title{
The Natural History of Metabolic Comorbidities in Turner Syndrome from Childhood to Early Adulthood: Comparison between 45,X Monosomy and Other Karyotypes
}

\author{
Yael Lebenthal ${ }^{1,2 *}$, Sigal Levy ${ }^{3}$, Efrat Sofrin-Drucker ${ }^{1}$, Nessia Nagelberg ${ }^{1}$, \\ Naomi Weintrob ${ }^{2,4}$, Shlomit Shalitin ${ }^{1,2}$, Liat de Vries ${ }^{1,2}$, Ariel Tenenbaum ${ }^{1,2}$, \\ Moshe Phillip ${ }^{1,2}$ and Liora Lazar ${ }^{1,2}$
}

${ }^{1}$ The Jesse Z and Sara Lea Shafer Institute for Endocrinology and Diabetes, National Center for Childhood Diabetes, Schneider Children's Medical Center of Israel, Petah Tikva, Israel, ${ }^{2}$ Sackler Faculty of Medicine, Tel Aviv University, Tel Aviv, Israel, ${ }^{3}$ Statistical Education Unit, The Academic College of Tel Aviv Yaffo, Jaffa, Israel, ${ }^{4}$ Pediatric Endocrinology and Diabetes Unit, Dana-Dwek Children's Hospital, Tel Aviv Sourasky Medical Center, Tel Aviv, Israel

OPEN ACCESS

Edited by:

Ahmet Uçar

Şişli Etfal Eğitim ve Araştırma

Hastanesi, Turkey

Reviewed by:

Korcan Demir,

Dokuz Eylül University, Turkey Huseyin Demirbilek,

Hacettepe University, Turkey

*Correspondence:

Yael Lebenthal

yael.lebenthal@gmail.com

Specialty section:

This article was submitted to

Pediatric Endocrinology,

a section of the journal

Frontiers in Endocrinology

Received: 13 December 2017

Accepted: 19 January 2018

Published: 09 February 2018

Citation:

Lebenthal Y, Levy S, SofrinDrucker E, Nagelberg N, Weintrob N, Shalitin S, de Vries L, Tenenbaum A

Phillip M and Lazar L (2018) The

Natural History of Metabolic Comorbidities in Turner Syndrome from Childhood to Early Adulthood:

Comparison between 45, $X$ Monosomy and Other Karyotypes.

Front. Endocrinol. 9:27.

doi: 10.3389/fendo.2018.00027
Objective: Patients with Turner syndrome (TS) are at increased risk for metabolic disorders. We aimed to delineate the occurrence and evolution of metabolic comorbidities in TS patients and to determine whether these differ in $45, \mathrm{X}$ monosomy and other karyotypes.

Methods: A longitudinal and cross-sectional retrospective cohort study was conducted in a tertiary pediatric endocrine unit during 1980-2016. Ninety-eight TS patients, 30 with 45,X monosomy were followed from childhood to early adulthood. Outcome measures included weight status, blood pressure (BP), glucose metabolism, and lipid profile.

Results: Longitudinal analysis showed a significant change in body mass index (BMI) percentiles over time $[F(3,115)=4.8, P=0.003]$. Age was associated with evolution of elevated BP [systolic BP: odds ratio $(\mathrm{OR})=0.91, P=0.003$; diastolic $\mathrm{BP}$ : $\mathrm{OR}=0.93$, $P=0.023$, impaired glucose metabolism (HbA1c: $\mathrm{OR}=1.08, P=0.029$; impaired glucose tolerance: $\mathrm{OR}=1.12, P=0.029$ ), and abnormal lipid profile (cholesterol: $\mathrm{OR}=1.06$, $P=0.01$; low-density lipoprotein cholesterol: $\mathrm{OR}=1.07, P=0.041$; high-density lipoprotein cholesterol: $\mathrm{OR}=1.07, P=0.033$ ). The occurrence of metabolic comorbidities was similar in 45,X monosomy and other karyotypes. Coexistence of multiple metabolic comorbidities was significantly higher in 45,X monosomy $[F(1,72)=4.81, P=0.032]$. $\mathrm{BMI}$ percentiles were positively correlated with metabolic comorbidities (occurrence and number) in each patient ( $r=0.35, P=0.002$ and $r=0.383, P=0.001$, respectively).

Conclusion: Our longitudinal study provides unique insights into the evolution of weight gain and metabolic disorders from childhood to early adulthood in TS patients. Since overweight and increasing age aggravate the risk for metabolic comorbidities, careful surveillance is warranted to prevent and control obesity already from childhood. The more prominent clustering of metabolic comorbidities in $45, \mathrm{X}$ monosomy underscores the importance of a more vigorous intervention in this group.

Keywords: Turner syndrome, karyotype, metabolic disturbances, obesity, impaired glucose metabolism 


\section{INTRODUCTION}

Turner syndrome (TS) is the most common chromosomal abnormality in girls, affecting approximately 1:2,500 of female live births (1). TS results from complete $\mathrm{X}$ chromosome monosomy, structural abnormality of the second $\mathrm{X}$ chromosome, or mosaicism, and has a characteristic phenotype and various comorbidities (2-4). Young adult women with TS are susceptible to a wide range of medical problems, including autoimmune disorders $(5,6)$, overweight and obesity (7), an increased risk for metabolic disorders such as glucose intolerance or dyslipidemia $(8,9)$, and osteopenia/osteoporosis (10). The coexistence of increased weight, impaired glucose metabolism, lipid abnormalities and hypertension ultimately increase their risk for acquired cardiovascular disease $(11,12)$. While the association between distinctive metabolic derangements and various TS karyotypes has been demonstrated in previous studies $(4,8,9)$ the evolution of these comorbidities from childhood to young adulthood in TS patients with various karyotypes has not been thoroughly assessed.

Our institutional policy is to offer continuing surveillance to TS patients till the mid-twenties by a multidisciplinary team aware of the complex and interrelated issues impacting on the health of these individuals. This practice has enabled us to carry out a comprehensive metabolic assessment of TS patients from childhood through puberty to young adulthood and to characterize the natural history of the metabolic comorbidities occurring in young adult women with TS.

The objectives of this longitudinal retrospective study were to assess the occurrence and evolution of overweight/obesity, hypertension, impaired glucose metabolism, and dyslipidemia in TS patients from childhood to early adulthood and to determine whether the prevalence and the natural history of these comorbidities differ in TS patients with 45,X monosomy and with other karyotypes.

\section{PATIENTS AND METHODS}

\section{Patients}

The medical files of 103 patients with TS confirmed by karyotyping who were followed at the Institution for Pediatric Endocrinology at the Schneider Children's Medical Center of Israel between the years 1980 and 2016 were reviewed. Ninety-eight cases fulfilled the inclusion criteria: karyotype documentation in the medical files; referral to our clinic prior to pubertal induction; and regular auxologic and blood pressure (BP) surveillance. Five patients [45,X $(n=3)$ and mosaicism $45, \mathrm{X} / 46, \mathrm{XX}(n=2)]$ were excluded from the study due to severe congenital malformations predisposing to hypertension (severe congenital cardiovascular disease and congenital anomalies of kidneys and urinary tract). The study cohort was categorized by karyotype into two groups: (1) 45,X (monosomy); (2) other karyotypes.

This study was approved by our institutional ethics committee. Because there was no identification of the patients for whom data was retrieved, informed consent by the patients was waived.

\section{Methods}

Our institutional policy consists of continuing clinical and laboratory surveillance of TS patients from referral to the midtwenties. Girls with TS are routinely scheduled for clinic visits every 4-6 months until attainment of full puberty and adult height, after which they are seen every 6 months until transition to adult endocrine clinics. Clinical assessment includes anthropometric measurements (height, weight), vital signs (heart rate and BP), complete physical examination, and dose adjustment of chronic medications, e.g., growth hormone (GH), estrogen and progesterone, or L-thyroxine. Screening for autoimmune thyroiditis (thyroid function test, antithyroid peroxidase, thyroglobulin antibodies) and celiac disease (anti-tissue transglutaminase, and immunoglobulin A levels) is performed from the age of 4 years onward. Screening for impaired glucose metabolism [fasting plasma glucose, hemoglobin Alc (HbAlc)], dyslipidemia, and liver disease is performed from the age of 8 years onward. All TS patients in whom cardiovascular defects were not identified at diagnosis undergo a reassessment of the cardiovascular system at 5-year intervals.

\section{Data Collection through Childhood and Early Adulthood}

The data obtained from the medical files included age at diagnosis, age at initiation and cessation of GH therapy, age at onset of spontaneous puberty and/or initiation of estrogen treatment, age at first menstrual bleeding, age at diagnosis of associated disorders (autoimmune diseases, hypertension, impaired glucose metabolism, dyslipidemia), and the use of chronic medications. The clinical and laboratory data (height, weight, pubertal stage, $\mathrm{BP}$, glucose, both fasting and in 2-h postoral glucose tolerance, fasting insulin levels and $\mathrm{HbAlc}$, lipid profile, and liver function tests) were extracted from the medical files at four timepoints: childhood (prior to pubertal induction), adolescence (1-2 years following onset of spontaneous puberty or initiation of estrogen replacement therapy), young adulthood (fully pubertal; age $<21$ years) and early adulthood (age $>21$ years; prior to transfer to adult endocrine clinics).

\section{Body Mass Index (BMI) Assessment}

Body mass index (weight in kilograms/square of height in meters) was calculated using the anthropometric measurements documented in the medical files. The evolution of BMI of the TS cohort from childhood through adolescence and young adulthood to early adulthood was assessed by using BMI percentiles. In childhood and adolescence, BMI values were converted to age- and sex-specific percentiles according to the CDC2000 (13). In adulthood, BMI values were converted according to the anthropometric reference data for all ages of the US population in 2003-2006 found in the National Health and Nutrition Examination Survey and National Center for Health Statistics (14). BMI percentiles were used as the index of body weight: underweight, $<5$ th percentile; normal weight, $\geq 5$ th to $<85$ th percentiles; overweight, $\geq 85$ th to $<95$ th percentiles; and obese, $\geq 95$ th percentile (15).

\section{BP Assessment}

Blood pressure was measured according to the recommendations of the National High Blood Pressure Education Program 
(NHBPEP) (16). In childhood, percentiles for systolic BP and diastolic BP were calculated according to height, sex, and age (16). Normal BP, prehypertension, and hypertension were defined according to the NHBPEP: BP was defined as normal when BP values were $<90$ th percentile, prehypertension-when either systolic and/or diastolic BP levels were $\geq 90$ th to the 95 th percentile, hypertension-when either systolic and/or diastolic BP level $\geq 95$ th percentile. Hypertension was classified as either stage 1 ( $\geq 95$ th to the $<99$ th percentile plus $5 \mathrm{~mm} \mathrm{Hg}$ ) or stage 2 ( $\geq 99$ th percentile plus $5 \mathrm{~mm} \mathrm{Hg}$ ). In adulthood, BP values were classified as: normal, <120/80; prehypertension, 120-139/80-89; stage 1 hypertension, 140-159/90-99; stage 2 hypertension, $\geq 160 / 100$ (17).

\section{Glucose Metabolism Assessment}

Fasting glucose levels were defined as follows: normal, $<100 \mathrm{mg} / \mathrm{dl}$; impaired fasting glucose, $100-125 \mathrm{mg} / \mathrm{dl}$; diabetes, $\geq 126 \mathrm{mg} / \mathrm{dl}$. In those cases which underwent an oral glucose tolerance test (OGTT), 2-h postprandial glucose levels following OGTT were defined as: normal, $<140 \mathrm{mg} / \mathrm{dl}$; impaired glucose tolerance, 140-199 mg/dl; diabetes, $\geq 200 \mathrm{mg} / \mathrm{dl}$. HbAlc levels were categorized as: normal, $<5.7 \%$; prediabetes, $5.7-6.4 \%$; diabetes, $\geq 6.5 \%$. Homeostasis model assessment-insulin resistance (HOMA-IR) was utilized as an insulin resistance index and was calculated by the following equation: [fasting glucose $(\mathrm{mg} / \mathrm{dl}) \times$ fasting insulin $(\mu \mathrm{U} / \mathrm{ml})] / 405$; resistance was defined as HOMA-IR $\geq 3$ (18).

\section{Lipid Profile Assessment}

Total cholesterol (TC), low-density lipoprotein cholesterol (LDL-c), high-density lipoprotein cholesterol (HDL-c), and triglycerides (TGs) were converted to age- and sex-specific percentiles according to the criteria of AAP Lipids in children aged 5-19 years (19). The lipid profile was classified as: desirable $<75$ th percentile/borderline high 75 th-90th percentile/high $>90$ th (TC, LDL-c, and TG) and low level <10th percentile/ average level 10th-25th/high level $>50$ th percentile (HDL-c). In adults, hypercholesterolemia was defined when TC levels were above $240 \mathrm{mg} / \mathrm{dl}$; elevated LDL-c was defined when LDL-c levels were above $130 \mathrm{mg} / \mathrm{dl}$; hypertriglyceridemia was defined when TG were above $150 \mathrm{mg} / \mathrm{dl}$ and low HDL-c was defined as levels $<50 \mathrm{mg} / \mathrm{dl}$.

\section{Statistical Analysis}

Data were analyzed using the IBM SPSS software (IBM SPSS Statistics for Windows, Version 24; IBM Corp., Armonk, NY, USA) and the HLM software version 7 (HLM Software). Data are presented as mean and SD or number and percentile, as appropriate. One-way analysis of variance (ANOVA) was used to test for group differences in quantitative, continuous variables; the $\chi^{2}$ test (or Fisher's exact test for small count tables) was used to compare groups in categorical variables. ANOVA with repeated measures was used to test for change in BMI percentile over time and the Friedman test was used to test for change over time in non-quantitative ordinal variables. Growth Curve Models with Logit link functions were used to test odds ratio (OR) of age on the risk of developing various metabolic comorbidities at early adulthood. The Pearson's correlation coefficient was used to test for association between quantitative variables. Logistic regression was used to test for risk factors for the occurrences of metabolic diseases. A $P$-value of $\leq 0.05$ was considered significant.

\section{RESULTS}

\section{Clinical Characteristics}

The study group consisted of 98 patients with TS, $30.6 \%(n=30)$ with 45 ,X monosomy and $69.4 \%(n=68)$ with other karyotypes: mosaicism 45,X/46, XX ( $n=21)$, isochromosomes $(\mathrm{Xq})$, or deletions $(n=29)$; a marker or ring chromosome $(n=10)$; karyotypes with Y chromosome material $(n=8)$.

The characteristics of the study population are shown in Table 1. The mean duration of follow-up in this cohort was 11.7 years, with no significant difference between 45 , $\mathrm{X}$ monosomy and other karyotypes. At diagnosis patients with monosomy were significantly younger than those displaying other karyotypes $(P=0.05)$. Spontaneous puberty occurred less frequently in TS girls with monosomy $(P=0.01)$. Age at onset of spontaneous puberty or age at initiation of pubertal induction were similar in both TS groups, while age at first menstrual bleeding was older in those with monosomy $(P=0.006)$. GH therapy was administered to $56 \%$ of the cohort; the rate of GH treatment, the age at initiation of therapy and the duration of therapy were similar in the two groups. Autoimmune thyroiditis was diagnosed in 33\% and celiac disease in $8.2 \%$ of the cohort, with no significant differences between groups. Liver diseases were found in $22.5 \%(n=22)$ of the patients: primary biliary cirrhosis in 2 , sclerosing cholangitis in 1 , autoimmune hepatitis in 6 , fatty liver in 8 , and undetermined etiology in 4 patients. In 10 patients, elevated liver enzymes were present already from adolescence.

TABLE 1 | Characteristics of Turner syndrome cohort.

\begin{tabular}{|c|c|c|c|c|}
\hline & $\begin{array}{c}\text { All } \\
\text { karyotypes }\end{array}$ & $\begin{array}{c}45, X \\
\text { monosomy }\end{array}$ & $\begin{array}{c}\text { Other } \\
\text { karyotypes }\end{array}$ & $P$ \\
\hline Number of subjects, $n$ (\%) & 98 & $30(30.6)$ & 68 (69.4) & \\
\hline Duration of follow-up (years) & $11.7 \pm 5.9$ & $11.7 \pm$ & $11.7=$ & 0.996 \\
\hline Age at diagnosis (years) & $6.7 \pm 4.5$ & $5.4 \pm 4.6$ & & 0.05 \\
\hline Spontaneous puberty, $n$ (\%) & $27(27.6)$ & $3(10)$ & $24(3$ & 0.01 \\
\hline $\begin{array}{l}\text { Age at spontaneous puberty } \\
\text { (years) }\end{array}$ & $11.8 \pm$ & & $11.9 \pm$ & 0.611 \\
\hline $\begin{array}{l}\text { Age at pubertal induction }{ }^{\mathrm{a}} \\
\text { (years) }\end{array}$ & $13.7 \pm 1.3$ & $13.8 \pm 1.3$ & $13.6 \pm 1.4$ & 0.465 \\
\hline $\begin{array}{l}\text { Age at first menstrual } \\
\text { bleeding (years) }\end{array}$ & $16.1 \pm 1.8$ & $17.0 \pm 1.6$ & $15.8 \pm 1.8$ & 0.006 \\
\hline $\begin{array}{l}\text { Growth hormone therapy, } \\
n(\%)\end{array}$ & $55(56.1)$ & $20(66.7)$ & $35(51.5)$ & 0.162 \\
\hline $\begin{array}{l}\text { Age at growth hormone } \\
\text { initiation (years) }\end{array}$ & $8.4 \pm 2.8$ & $9.1 \pm 2.9$ & $8.0 \pm 2.7$ & 0.517 \\
\hline Age at last clinic visit (years) & $21.3 \pm 6.0$ & $21.4 \pm 5.8$ & $21.2 \pm 6.0$ & 0.900 \\
\hline Autoimmune thyroiditis, $n$ (\%) & & & & 0.193 \\
\hline Celiac disease, $n(\%)$ & 8/94 (8.5) & $4 / 30(13.3)$ & 4/64 (6.3) & 0.262 \\
\hline Liver disease, $n$ (\%) & $22(22.5)$ & $5(16.7)$ & $17(25.0)$ & 0.362 \\
\hline
\end{tabular}

Data expressed as mean and SD unless otherwise specified.

Bold font represents $P$ values which are statistically significant.

${ }^{3} 3$ of the TS cohort were $<10$ years of age at data collection.

${ }^{b} 19$ of the TS cohort have not attained menarche; 3 prepubertal and 16 pubertal girls ( $\leq$ Tanner 4). 


\section{Evolution of Weight Status and Metabolic Comorbidities}

In childhood, metabolic impairments were detected in $20-25 \%$ of the studied girls: overweight/obesity in $15 \%$, elevated systolic and/or diastolic BP in 22\%, impaired glucose metabolism in $10 \%$, and increased lipid levels (TG and TC) in $27 \%$.

Longitudinal analysis of weight status (expressed as BMI percentile) at three times points (from childhood to young adulthood) showed a significant change over time in both those with 45,X monosomy and those with other chromosomal abnormalities $[F(2,132)=3.1, P=0.05]$, with a marginally significant difference between groups $[F(1,66)=3.7, P=0.06]$ and with no significant between-group interactions. Longitudinal analysis from childhood to early adulthood showed a significant change in BMI percentiles over time $[F(3,115)=4.8, P=0.003]$. Sidak post hoc analysis showed that BMI percentile at early adulthood was significantly lower than at adolescence or young adulthood.

Longitudinal analysis (using Growth Curve Models) of metabolic comorbidities from childhood to early adulthood showed that age was associated with evolution of elevated BP percentiles (SBP: OR $=0.91, P=0.003$; DBP: $\mathrm{OR}=0.93$, $P=0.023)$, impaired glucose metabolism (HbA1c: $\mathrm{OR}=1.08$,
$P=0.029$; IGT: $\mathrm{OR}=1.12, P=0.029)$, and abnormal lipid profile (TC: $\mathrm{OR}=1.06, P=0.01$; LDL-c: $\mathrm{OR}=1.07, P=0.041$; HDL-c: $\mathrm{OR}=1.07, P=0.033)$.

\section{Cross-sectional Analysis of Weight Status and Metabolic Comorbidities Weight Status}

At childhood and adolescence, the mean BMI percentile of the 45 , X monosomy was significantly higher than that of the other chromosomal abnormalities $(P=0.037$ and $P=0.035$, respectively), while at young adulthood and early adulthood it was similar in both groups (Tables 2 and 3). The distribution of BMI weight categories (underweight, normal weight, overweight, and obese) at the follow-up timepoints was similar for both groups.

\section{Blood Pressure}

The distribution of BP categories (normal BP, pre-hypertension, stage 1 and stage 2 hypertension) at the follow-up timepoints was similar for all groups. The prevalence of elevated BP at childhood, adolescence, young adulthood, and early adulthood was $21.8 \%$, $35.2 \%, 25.7 \%$, and $21.8 \%$ for SBP and $23 \%, 33 \%, 32.4 \%$, and $14.5 \%$ for DBP, respectively.

TABLE 2 | Cross-sectional analysis of weight status and blood pressure in 45,X monosomy and other karyotypes at childhood, adolescence, young, and early adulthood.

\begin{tabular}{|c|c|c|c|c|c|c|c|c|c|c|c|c|}
\hline & \multicolumn{3}{|c|}{ Childhood } & \multicolumn{3}{|c|}{ Adolescence } & \multicolumn{3}{|c|}{ Young adulthood } & \multicolumn{3}{|c|}{ Early adulthood } \\
\hline & $45, x$ & $\begin{array}{c}\text { Other } \\
\text { karyotypes }\end{array}$ & $P$ & $45, X$ & $\begin{array}{c}\text { Other } \\
\text { karyotypes }\end{array}$ & $\boldsymbol{P}$ & $45, x$ & $\begin{array}{c}\text { Other } \\
\text { karyotypes }\end{array}$ & $P$ & $45, X$ & $\begin{array}{c}\text { Other } \\
\text { karyotypes }\end{array}$ & $P$ \\
\hline Number & 27 & 60 & & 29 & 62 & & 24 & 50 & & 18 & 37 & \\
\hline Age (years) & $9.2(1.0)$ & $9.1(1.4)$ & 0.777 & $13.5(1.3)$ & $13.7(1.2)$ & 0.455 & $19.1(1.2)$ & $19.2(1.4)$ & 0.852 & $25.6(2.3)$ & $25.9(1.7)$ & 0.514 \\
\hline \multicolumn{13}{|l|}{ Weight status } \\
\hline BMl $\left(\mathrm{kg} / \mathrm{m}^{2}\right)$ & $18(2.7)$ & $17.0(2.4)$ & 0.065 & $21.8(4.2)$ & $20.3(3.1)$ & 0.044 & $25.7(6.1)$ & $23.8(4.5)$ & 0.132 & $25.6(5.1)$ & $25.2(5.7)$ & 0.784 \\
\hline BMI percentile & $65.0(20.6)$ & $52.5(27.2)$ & 0.037 & $68.3(23.8)$ & $56.1(26.0)$ & 0.035 & $68.6(29.1)$ & $61.4(25.4)$ & 0.279 & $50.1(25.3)$ & $48.1(22.8)$ & 0.763 \\
\hline \multicolumn{13}{|c|}{ Weight categories, \% } \\
\hline Underweight & 0 & 0 & & 3.4 & 1.6 & & 8.3 & 2.0 & & 0 & 2.7 & \\
\hline Healthy weight & 81.5 & 86.7 & & 65.5 & 85.5 & & 54.2 & 78.0 & & 83.3 & 89.2 & \\
\hline Overweight & 7.4 & 11.6 & 0.173 & 20.7 & 9.7 & 0.117 & 20.8 & 12.0 & 0.151 & 16.7 & 5.4 & 0.539 \\
\hline Obesity & 11.1 & 1.7 & & 10.3 & 3.2 & & 16.6 & 8.0 & & 0 & 2.7 & \\
\hline \multicolumn{13}{|l|}{ Blood pressure } \\
\hline $\mathrm{SBP}(\mathrm{mmHg})$ & $96.5(8.2)$ & $95.8(9.6)$ & 0.761 & $108.1(13.5)$ & $105.2(12.6)$ & 0.319 & $113.5(13.3)$ & $110.4(11.9)$ & 0.318 & 115.9 (10.9) & $112.7(14.5)$ & 0.420 \\
\hline SBP percentile & $57.4(15.8)$ & $59.9(17.9)$ & 0.540 & $62.9(20.4)$ & $65.0(21.0)$ & 0.667 & $63.1(21.0)$ & $60.6(19.1)$ & 0.602 & NA & NA & \\
\hline \multicolumn{13}{|c|}{ SBP categories, \% } \\
\hline Normal SBP & 81.5 & 75 & & 65.5 & 64.5 & & 70.8 & 76.0 & & 72.2 & 81.1 & \\
\hline Pre-HTN & 18.5 & 18.3 & & 10.3 & 16.1 & & 12.5 & 10.0 & & 27.8 & 13.5 & \\
\hline HTN 1 & 0 & 1.7 & 1 & 13.8 & 9.7 & 0.864 & 4.2 & 8.0 & 0.736 & 0 & 2.7 & 0.528 \\
\hline HTN 2 & 0 & 3.3 & & 10.3 & 9.7 & & 12.5 & 6.0 & & 0 & 2.7 & \\
\hline $\mathrm{DBP}(\mathrm{mmHg})$ & $60.4(6.8)$ & $59.1(7.5)$ & 0.443 & $67.3(10.0)$ & $65.6(8.2)$ & 0.386 & $71.5(8.3)$ & $69.2(7.9)$ & 0.247 & $72.0(10.1)$ & $71.0(9.2)$ & 0.714 \\
\hline DBP percentile & $60.4(17.9)$ & $59.0(17.1)$ & 0.731 & $62.8(20.4)$ & $64.3(20.3)$ & 0.717 & $64.8(20.8)$ & $63.6(19.7)$ & 0.809 & NA & NA & \\
\hline \multicolumn{13}{|c|}{ DBP categories (\%) } \\
\hline Normal DBP & 74.1 & 76.7 & & 71.4 & 66.1 & & 66.6 & 68.0 & & 83.3 & 86.5 & \\
\hline Pre-HTN & 25.9 & 18.3 & & 7.1 & 21 & & 16.7 & 24.0 & & 11.1 & 8.1 & \\
\hline HTN 1 & 0 & 3.3 & 1 & 19.7 & 9.7 & 0.282 & 16.7 & 6.0 & 0.432 & 5.6 & 5.4 & 0.837 \\
\hline HTN 2 & 0 & 0 & & 3.6 & 3.2 & & 0 & 2.0 & & 0 & 0 & \\
\hline
\end{tabular}

Data are presented as mean (SD) or percentage of patients.

Bold font represents $P$ values which are statistically significant.

BMI, body mass index; SBP, systolic blood pressure; DBP, diastolic blood pressure; HTN, hypertension; NA, not applicable. 
TABLE 3 | Cross-sectional analysis of glucose metabolism and lipid profile in 45,X monosomy and other karyotypes at childhood, adolescence, young, and early adulthood.

\begin{tabular}{|c|c|c|c|c|c|c|c|c|c|c|c|c|}
\hline & \multicolumn{3}{|c|}{ Childhood } & \multicolumn{3}{|c|}{ Adolescence } & \multicolumn{3}{|c|}{ Young adulthood } & \multicolumn{3}{|c|}{ Early adulthood } \\
\hline & $\begin{array}{c}45, X \\
\text { monosomy }\end{array}$ & $\begin{array}{c}\text { Other } \\
\text { karyotypes }\end{array}$ & $P$ & $\begin{array}{c}45, X \\
\text { monosomy }\end{array}$ & $\begin{array}{c}\text { Other } \\
\text { karyotypes }\end{array}$ & $P$ & $\begin{array}{c}45, X \\
\text { monosomy }\end{array}$ & $\begin{array}{c}\text { Other } \\
\text { karyotypes }\end{array}$ & $P$ & $\begin{array}{c}45, X \\
\text { monosomy }\end{array}$ & $\begin{array}{c}\text { Other } \\
\text { karyotypes }\end{array}$ & $P$ \\
\hline Age (years) & $9.2(1.0)$ & $9.1(1.4)$ & 0.777 & $13.5(1.3)$ & $13.7(1.2)$ & 0.455 & $19.1(1.2)$ & $19.2(1.4)$ & 0.852 & $25.6(2.3)$ & $25.9(1.7)$ & 0.514 \\
\hline \multicolumn{13}{|l|}{ Glucose metabolism } \\
\hline Number & 27 & 60 & & 29 & 62 & & 24 & 50 & & 18 & 37 & \\
\hline $\mathrm{FPG}(\mathrm{mg} / \mathrm{dl})$ & $87.9(7.1)$ & $82.1(8.2)$ & 0.002 & $88.2(9.5)$ & $85.5(9.5)$ & 0.205 & $85.4(9.3)$ & $85.6(13.3)$ & 0.954 & $83.1(9.4)$ & $83.2(8.4)$ & 0.960 \\
\hline Impaired FPG (\%) & 0 & 1.7 & 1 & 6.9 & 6.5 & 1 & 8.3 & 8.0 & 1 & 5.6 & 2.7 & 0.535 \\
\hline $\mathrm{HbA1c}(\%)$ & $5.3(0.4)$ & $5.1(0.3)$ & 0.278 & $5.2(0.4)$ & $5.3(0.4)$ & 0.251 & $5.3(1.3)$ & $5.2(0.3)$ & 0.212 & $5.3(0.4)$ & $5.4(0.4)$ & 0.428 \\
\hline \multicolumn{13}{|l|}{ Oral glucose tolerance test } \\
\hline Number & 7 & 13 & & 15 & 33 & & 15 & 27 & & 8 & 9 & \\
\hline 2 h postload glucose (mg/dl) & $117.5(36.9)$ & $88.4(14.2)$ & 0.029 & $111.4(35.5)$ & $119.6(23.4)$ & 0.352 & $115.8(37.8)$ & $125.3(47.0)$ & 0.25 & $128.9(47.7)$ & $132.5(24.4)$ & 0.838 \\
\hline IGT (\%) & 14.3 & 7.7 & 1 & 20.0 & 15.1 & 0.676 & 26.7 & 18.5 & 0.537 & 50.0 & 33.0 & 0.637 \\
\hline HOMA-IR > $3(\%)$ & 14.3 & 23.1 & 1 & 20.0 & 21.2 & 1 & 33.3 & 33.3 & 1 & 12.5 & 22.2 & 1 \\
\hline \multicolumn{13}{|l|}{ Lipid profile } \\
\hline TC & 26 & 55 & & 27 & 61 & & 24 & 44 & & 16 & 37 & \\
\hline $\mathrm{TC}(\mathrm{mg} / \mathrm{dl})$ & $170(28.9)$ & $173.6(26.1)$ & 0.574 & $180.8(37.4)$ & $175.8(32)$ & 0.522 & $194.4(36.5)$ & $172.5(36.1)$ & 0.020 & $197.6(42.7)$ & $183.1(33.7)$ & 0.192 \\
\hline$\leq 50$ th centile (\%) & 50 & 43.6 & \multirow{5}{*}{0.555} & 29.2 & 45.5 & \multirow{5}{*}{0.436} & 29.2 & 45.5 & & 37.5 & 35.1 & \multirow{5}{*}{0.496} \\
\hline 75th centile (\%) & 23.1 & 32.7 & & 16.7 & 18.2 & & 16.6 & 18.2 & \multirow{4}{*}{0.436} & 6.3 & 24.3 & \\
\hline 90th centile (\%) & 15.4 & 7.3 & & 16.7 & 15.9 & & 16.6 & 15.9 & & 12.5 & 8.1 & \\
\hline$\geq 95$ th centile (\%) & 11.5 & 16.4 & & 37.5 & 20.5 & & 37.5 & 20.5 & & 43.8 & 32.4 & \\
\hline LDL-c, $n$ & 21 & 38 & & 22 & 46 & & 19 & 37 & & 13 & 35 & \\
\hline LDL-c (mg/dl) & $96.4(21.8)$ & $101.8(20.8)$ & 0.360 & $106.3(30.6)$ & $102.8(24.7)$ & 0.616 & $115.0(32.2)$ & $100.3(24.6)$ & 0.063 & $113.3(29.7)$ & $108.2(29.8)$ & 0.599 \\
\hline$\leq 50$ th centile $(\%)$ & 61.9 & 55.3 & \multirow{5}{*}{0.935} & 36.8 & 51.4 & \multirow{5}{*}{0.271} & 36.8 & 51.4 & & 38.5 & 40 & \multirow{5}{*}{0.716} \\
\hline 75th centile (\%) & 28.5 & 26.3 & & 36.8 & 35.1 & & 36.8 & 35.1 & \multirow{4}{*}{0.271} & 15.4 & 28.6 & \\
\hline 90th centile (\%) & 4.8 & 7.9 & & 0 & 5.4 & & 0 & 5.4 & & 15.4 & 8.6 & \\
\hline z95th centile (\%) & 4.8 & 10.5 & & 26.3 & 8.1 & & 26.3 & 8.1 & & 30.8 & 17.1 & \\
\hline HDL-c, $n$ & 21 & 39 & & 23 & 47 & & 19 & 38 & & 13 & 35 & \\
\hline HDL-c (mg/dl) & $56.8(13.7)$ & 55.4 (11.6) & 0.677 & 56.5 (16.3) & $57.4(11.9)$ & 0.790 & $56.2(13.8)$ & $54.2(15.3)$ & 0.646 & $63.6(17.7)$ & 56.7 (12.5) & 0.134 \\
\hline$\geq 50$ th centile (\%) & 76.2 & 76.9 & \multirow{5}{*}{0.945} & 73.7 & 60.5 & \multirow{5}{*}{0.718} & 73.7 & 60.5 & & 84.6 & 71.5 & \multirow{5}{*}{0.720} \\
\hline 25th centile (\%) & 14.2 & 10.3 & & 15.8 & 39.5 & & 15.8 & 21.1 & \multirow{4}{*}{0.718} & 7.7 & 20.0 & \\
\hline 10th centile (\%) & 4.8 & 7.7 & & 0 & 18.4 & & 0 & 7.9 & & 7.7 & 5.7 & \\
\hline$\leq 5$ th centile $(\%)$ & 4.8 & 5.1 & & 10.5 & 10.5 & & 10.5 & 10.5 & & 0 & 2.9 & \\
\hline TG, $n$ & 24 & 43 & & 23 & 49 & & 20 & 39 & & 15 & 35 & \\
\hline $\mathrm{TG}(\mathrm{mg} / \mathrm{dl})$ & $80(34.8)$ & $84.8(34.7)$ & 0.587 & 97.7 (52.3) & 85 (33.5) & 0.219 & $104.9(55.5)$ & $81.9(25.4)$ & 0.032 & $115.7(81.3)$ & $91.4(46)$ & 0.198 \\
\hline$\leq 50$ th centile (\%) & 54.2 & 41.8 & \multirow{4}{*}{0.718} & 20.0 & 56.4 & \multirow{4}{*}{0.039} & 40.0 & 54.4 & \multirow{4}{*}{0.039} & 46.1 & 40.0 & \multirow{4}{*}{0.434} \\
\hline 75th centile (\%) & 20.8 & 30.2 & & 15.0 & 30.8 & & 15.0 & 30.8 & & 7.7 & 22.9 & \\
\hline 90th centile (\%) & 8.3 & 14.0 & & 10.0 & 5.1 & & 10.0 & 5.1 & & 7.7 & 17.1 & \\
\hline 295th centile (\%) & 16.7 & 14.0 & & 35.0 & 7.7 & & 35.0 & 7.7 & & 38.5 & 20.0 & \\
\hline
\end{tabular}

Data expressed as mean (SD) unless otherwise specified.

Bold font represents $P$ values which are statistically significant.

n, number; FPG, fasting plasma glucose; IGT, impaired glucose tolerance; HOMA-IR, homeostatic model assessment of insulin resistance; TC, total cholesterol; LDL-c, low-density lipoprotein cholesterol; HDL-c, high-density lipoprotein cholesterol; TG, triglycerides. 


\section{Glucose Metabolism}

Fasting glucose, 2-h post-OGTT glucose, and HbA1c levels were within the normal range in most of the studied girls at all follow-up timepoints. Impaired fasting glucose was documented in $6.6 \%$ of the girls during adolescence and in $8.1 \%$ at young adulthood. Impaired glucose tolerance was documented already from childhood, with increasing prevalence during adolescence, young adulthood and early adulthood (10\%, 16.7\%, $21.4 \%$, and $41.2 \%$, respectively). Insulin resistance (HOMA-IR) was detected in $20 \%$ of the patients tested during childhood and adolescence, and in $33.3 \%$ of the patients tested at young adulthood. Glucose metabolism parameters showed no statistical difference between the patients with the 45,X monosomy and those with all other karyotypes.

\section{Lipid Profile}

At the four follow-up timepoints the mean TC, LDL-c, HDL-c and TG levels of the entire cohort were relatively normal, with no significant difference between the two groups with the exception of higher mean TG levels at young adulthood in the 45,X monosomy group $(P=0.032)$. The distribution of TC and LDL-c percentiles ( $\leq 50$ th $\%, 75$ th $\%, 90$ th $\%$, and $\geq 95$ th $\%$ ) and of HDL-c percentiles ( $\geq 50$ th $\%, 25$ th $\%, 10$ th $\%$, and $\leq 5$ th $\%$ ) at the four follow-up timepoints was similar in the two groups; the prevalence of elevated TG categories at adolescence and young adulthood was higher in the $45, \mathrm{X}$ monosomy group $(P=0.039$ for both timepoints).

\section{Cooccurrence of Metabolic Comorbidities}

Cooccurrence of metabolic comorbidities was found in $55.4 \%$ of the cohort. There was a significant difference between those with 45 , X monosomy and those with other chromosome abnormalities in both the frequency [79.2\% and $\left.44 \%, \chi^{2}(1)=8.1, P=0.004\right]$ and number of comorbidities $[2.4 \pm 1.5$ and $1.6 \pm 1.3, F(1,72)=4.81$, $P=0.032]$.

\section{Correlations}

Body mass index percentiles of the cohort at childhood were positively correlated with BMI percentiles during adolescence ( $r=0.69 ; P<0.001)$, young adulthood $(r=0.43 ; P<0.001)$, and early adulthood $(r=0.33 ; P=0.021)$; BMI at adolescence was positively correlated with BMI percentiles during young adulthood $(r=0.76 ; P<0.001)$ and early adulthood $(r=0.65$; $P<0.001)$; BMI at young adulthood was positively correlated with BMI percentiles during early adulthood $(r=0.76 ; P<0.001)$ (Figure 1).

Body mass index percentiles were positively correlated with the metabolic comorbidities: SBP percentiles (childhood $r=0.21, P=0.05$; young adulthood $r=0.32, P=0.005$, early adulthood $r=0.35, P=0.009$ ), DBP percentiles (young adulthood $r=0.24, P=0.043$ ), FPG (adolescence $r=0.24, P=0.020$; young adulthood $r=0.31, P=0.007$; early adulthood $r=0.33$, $P=0.016$ ), HbA1c (early adulthood $r=0.38, P=0.010$ ), and TG levels (childhood $r=0.27, P=0.028$; young adulthood $r=0.25$, $P=0.053$ ). The occurrence of coexistent metabolic comorbidities and the number of comorbidities in each patient were positively correlated with BMI percentile $(r=0.35, P=0.002$ and $r=0.383$, $P=0.001$, respectively).

Logistic regression analysis showed that karyotype, $\mathrm{GH}$ therapy, HRT, autoimmune thyroid disease, or celiac disease were not associated with the occurrence of metabolic comorbidities.

\section{DISCUSSION}

Although the cardinal manifestations of TS during childhood and adolescence are short stature and sexual infantilism, a wide spectrum of cardiometabolic risk factors (overweight, hypertension, impaired glucose metabolism and dyslipidemia) also has its start in childhood, increasing the risk for atherosclerosis and cardiovascular disease across the patient's lifespan (11, 12, 20-23). The evolution of these metabolic disorders from childhood to adulthood has not yet been completely defined. In this longitudinal retrospective study of a relatively large cohort of TS patients followed in our institution from childhood to early adulthood, we found that the prevalence of overweight/ obesity and cardiometabolic disorders identified in childhood increased with age. Since adolescence the increased rate and cooccurrence of the metabolic disorders in each patient were associated with overweight/obesity. A more prominent clustering of metabolic comorbidities in 45, X monosomy were found. Our findings confirm previous observations that an abnormal metabolic profile appears at a relatively young age in girls with TS $(8,11,12,24-27)$.

Although the development of the comorbidities from childhood through adolescence to young/early adulthood was similar in all these TS patients, both those with 45,X monosomy and those with other karyotypes, clustering of metabolic risk factors was more prominent in those with 45,X monosomy. It has been suggested that $\mathrm{X}$ chromosome gene dosage (complete absence of the second X chromosome or haploinsufficiency of genes on the $\mathrm{X}$ chromosome) has an impact on the occurrence of metabolic disorders $(9,28,29)$. Our data, however, showed a similar prevalence of overweight, elevated BP, impaired glucose metabolism, and abnormal lipid profile in TS patients with 45,X monosomy and those with other karyotypes, not only during childhood but also through adolescence and young adulthood. These findings are consistent with those of Irzyniec and Jeż, who demonstrated a similar rate of metabolic risk factors in all the karyotype subgroups (30), but in contrast to previous studies reporting a higher rate of metabolic disorders among patients with 45,X monosomy $(4,9,28,29)$. The parental origin of the single $\mathrm{X}$-chromosome has also been linked to the incidence of metabolic disorders. Women with a single maternal $\mathrm{X}$-chromosome were found to be more prone to excessive visceral adiposity and dyslipidemia $(9,31)$. Regrettably, such an analysis was not performed in our studied cohort and therefore we cannot confirm or negate possible X-chromosome gene imprinting.

A plausible explanation for the early development of metabolic impairments could have been overweight and obesity. However, in a substantial number of the girls in our study already 


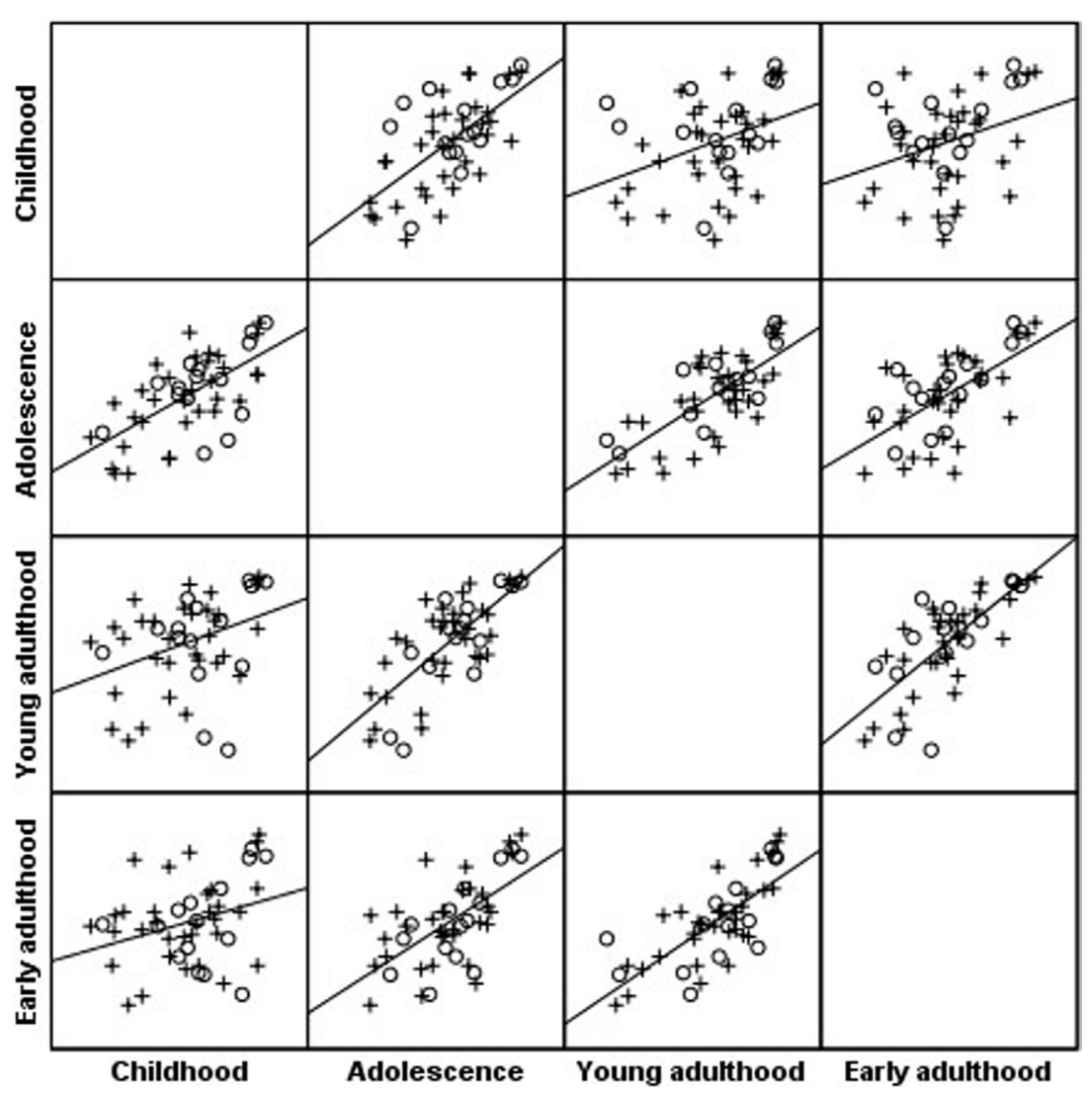

FIGURE 1 | Scatterplot matrix of body mass index (BMI) percentile along four timepoints: BMl percentiles of the Turner syndrome cohort at childhood were positively correlated with BMl percentiles during adolescence $(r=0.69 ; P<0.001)$, young adulthood $(r=0.43 ; P<0.001)$, and early adulthood $(r=0.33$; $P=0.021)$; BMl at adolescence was positively correlated with BMl percentiles during young adulthood $(r=0.76 ; P<0.001)$ and early adulthood $(r=0.65$; $P<0.001)$; BMl at young adulthood was positively correlated with BMl percentiles during early adulthood $(r=0.76 ; P<0.001)$. $0,45, \mathrm{X}$ monosomy, $\mathrm{X}$, all other karyotypes.

displaying cardiometabolic risk factors during childhood the BMI percentile was normal. As in other studies, our findings showed that hypertension, impaired glucose metabolism and dyslipidemia were not associated with body weight in young girls with TS $(7,24-27)$. It would therefore appear that these early metabolic derangements may be attributed to risk factors inherent to TS: impaired glucose metabolism-to pancreatic beta cell dysfunction and decreased insulin secretory response to glucose $(8,12)$; abnormal circadian BP rhythm and elevated $\mathrm{BP}$ - to autonomic dysfunction with altered vascular tone $(7,32)$. It was, however, clear that increased weight aggravated the metabolic profile of these patients in adolescence and young adulthood.

The evolution of weight gain observed in our TS patients was characterized by an increasing rate of overweight and obesity from childhood to young adulthood in the entire cohort, with BMI percentile consistently higher in girls with 45,X monosomy. It is noteworthy that a high BMI percentile in childhood predicted overweight and obesity in adolescence and young/ early adulthood. These findings agree with those of earlier and more recent studies (33-36). The natural history of the metabolic risk factors in our study cohort revealed a sustained increase in the prevalence of the metabolic comorbidities from childhood to young/early adulthood. In agreement with previous studies, we found that the occurrence of hypertension, impaired glucose metabolism and hypertriglyceridemia were positively correlated with the increased BMI $(7,12)$. Interestingly, clustering of several metabolic risk factors was more prevalent in those of the TS patients with 45,X monosomy who displayed increased BMI since adolescence.

In this observational longitudinal study, the issue of causality of the metabolic comorbidities could not be addressed. There is, however, an indication that increased weight during adolescence and young adulthood aggravated insulin resistance, glucose intolerance and hypertriglyceridemia, and contributed to the development of hypertension. Importantly, and similarly to previous reports, we found no evidence that GH treatment, age at onset of spontaneous puberty or at induction of puberty, or estrogen treatment (oral or transdermal) had any impact either on weight gain or on the development of metabolic comorbidities in our patients with TS (37-39).

Obesity, hypertension, impaired glucose metabolism and hyperlipidemia when identified in childhood are all modifiable risk factors. Thus, our findings come to emphasize the importance 
of regular assessment of weight status and metabolic risk factors in girls with TS from early childhood. Early detection of increased weight gain and of metabolic risk factors allows timely intervention to prevent the overweight and the development of metabolic impairments and their progression toward overt metabolic comorbidities.

The main strength of our study was the longitudinal data obtained from a relatively large cohort of TS patients followed in our tertiary center from childhood to early adulthood. The main limitation of our study is the lack of clinical measures of body adiposity such as skinfold thickness, waist circumference, bioelectrical impedance, or dual-energy X-ray absorptiometry as well as the lack of quantitatively determined atherosclerosis (intimal-medial thickness) by carotid arterial ultrasound. Despite several limitations, BMI is considered a reliable and clinically valid screening tool for obesity. Furthermore, our data include markers of impaired glucose metabolism associated with adiposity such as measures of insulin resistance (HOMA-IR) and IGT. Another limitation is lack of information regarding the origin of the missed X-chromosome.

In conclusion, TS patients followed in our tertiary center from childhood to early adulthood showed a sustained increase in the prevalence of their metabolic comorbidities. While the abnormal metabolic profile during childhood most likely stemmed from risk factors inherent to TS, the aggravation of the metabolic derangements was associated with the increased weight observed during adolescence and young adulthood. Therefore, regular screening of weight and metabolic risk factors and efforts to prevent and control obesity in young TS patients should be accorded a high priority already from childhood. The more prominent clustering of metabolic comorbidities in TS girls with 45 , X monosomy and those with overweight/obesity underscores the importance of a still more vigorous intervention in these groups. Future research should address whether modification of

\section{REFERENCES}

1. Nielsen J, Wohlert M. Chromosome abnormalities found among 34,910 newborn children: results from a 13-year incidence study in Arhus, Denmark. Hum Genet (1991) 87(1):81-3. doi:10.1007/BF01213097

2. Sybert VP, McCauley E. Turner's syndrome. N Engl J Med (2004) 351(12): 1227-38. doi:10.1056/NEJMra030360

3. Bondy CA, Turner Syndrome Study Group. Care of girls and women with Turner syndrome: a guideline of the Turner Syndrome Study Group. J Clin Endocrinol Metab (2007) 92(1):10-25. doi:10.1210/jc.2006-1374

4. Cameron-Pimblett A, La Rosa C, King TFJ, Davies MC, Conway GS. The Turner syndrome life course project: karyotype-phenotype analyses across the lifespan. Clin Endocrinol (Oxf) (2017) 87(5):532-8. doi:10.1111/cen. 13394

5. Livadas S, Xekouki P, Fouka F, Kanaka-Gantenbein C, Kaloumenou I, Mavrou A, et al. Prevalence of thyroid dysfunction in Turner's syndrome: a long-term follow-up study and brief literature review. Thyroid (2005) 15(9):1061-6. doi:10.1089/thy.2005.15.1061

6. Bonamico M, Pasquino AM, Mariani P, Danesi HM, Culasso F, Mazzanti L, et al. Prevalence and clinical picture of celiac disease in Turner syndrome. J Clin Endocrinol Metab (2002) 87(12):5495-8. doi:10.1210/jc.2002-020855

7. Gravholt CH, Hjerrild BE, Mosekilde L, Hansen TK, Rasmussen LM, Frystyk J, et al. Body composition is distinctly altered in Turner syndrome: relations to glucose metabolism, circulating adipokines, and endothelial adhesion molecules. Eur J Endocrinol (2006) 155(4):583-92. these variables at a young age can alter the metabolic outcomes in adulthood.

\section{ETHICS STATEMENT}

This study was carried out in accordance with the recommendations of the Rabin Medical Center Institutional Review Board. The protocol was approved by the institutional review board, because there was no identification of the patients for whom data was retrieved, informed consent by the patients was waived.

\section{AUTHOR CONTRIBUTIONS}

YL and LL contributed to the conception and design of the study, acquisition of the data and interpretation of data, drafted the article, revised it, and gave their final approval of the version to be published. SL contributed to the data analysis, data interpretation, and gave final approval of the version to be published. ES-D contributed to the conception of the study, acquisition of data, and gave her final approval of the version to be published. NN contributed to acquisition of data and gave final approval of the version to be published. NW, SS, LV, AT, and MP contributed to acquisition of data, revised the manuscript critically for important intellectual content, and gave their final approval of the version to be published.

\section{ACKNOWLEDGMENTS}

The authors thank Ruth Fradkin for editorial assistance.

\section{FUNDING}

This research did not receive any specific grant from any funding agency in the public, commercial, or not-for-profit sector.

8. Bakalov VK, Cooley MM, Quon MJ, Luo ML, Yanovski JA, Nelson LM, et al. Impaired insulin secretion in the Turner metabolic syndrome. J Clin Endocrinol Metab (2004) 89(7):3516-20. doi:10.1210/jc.2004-0122

9. Van PL, Bakalov VK, Bondy CA. Monosomy for the X-chromosome is associated with an atherogenic lipid profile. J Clin Endocrinol Metab (2006) 91(8):2867-70. doi:10.1210/jc.2006-0503

10. Bakalov VK, Chen ML, Baron J, Hanton LB, Reynolds JC, Stratakis CA, et al. Bone mineral density and fractures in Turner syndrome. Am J Med (2003) 115(4):259-64. doi:10.1016/S0002-9343(03)00364-4

11. Pirgon Ö, Atabek ME, Oran B, Güçlü R. Atherogenic lipid profile and systolic blood pressure are associated with carotid artery intima-media thickness in children with Turner syndrome. JClin Res Pediatr Endocrinol (2008) 1(2):62-71. doi: $10.4008 /$ jcrpe.v1i2.9

12. O'Gorman CS, Syme C, Lang J, Bradley TJ, Wells GD, Hamilton JK. An evaluation of early cardiometabolic risk factors in children and adolescents with Turner syndrome. Clin Endocrinol (Oxf) (2013) 78(6):907-13. doi:10.1111/ cen.12079

13. Kuczmarski RJ, Ogden CL, Guo SS, Grummer-Strawn LM, Flegal KM, Mei Z, et al. 2000 CDC Growth Charts for the United States: methods and development. Vital Health Stat 11 (2002) 246(1):1-190.

14. McDowell MA, Fryar CD, Ogden CL, Flegal KM. Anthropometric reference data for children and adults: United States, 2003-2006. Natl Health Stat Report (2008) 10:1-48.

15. Ogden CL, Flegal KM. Changes in terminology for childhood overweight and obesity. Natl Health Stat Report (2010) 25:1-5. 
16. National High Blood Pressure Education Program Working Group on High Blood Pressure in Children and Adolescents. The fourth report on the diagnosis, evaluation, and treatment of high blood pressure in children and adolescents. Pediatrics (2005) 114(2 Suppl 4th Report):555-76. doi:10.1542/ peds.114.2.S2.555

17. Chobanian AV, Bakris GL, Black HR, Cushman WC, Green LA, Izzo JL Jr, et al. The Seventh Report of the Joint National Committee on Prevention, Detection, Evaluation, and Treatment of High Blood Pressure: the JNC 7 report. JAMA (2003) 289(19):2560-72. doi:10.1001/jama.289.19.2560

18. Matthews DR, Hosker JP, Rudenski AS, Naylor BA, Treacher DF, Turner RC. Homeostasis model assessment: insulin resistance and beta-cell function from fasting plasma glucose and insulin concentrations in man. Diabetologia (1985) 28(7):412-9. doi:10.1007/BF00280883

19. Daniels SR, Greer FR; Committee on Nutrition. Lipid screening and cardiovascular health in childhood. Pediatrics (2008) 122(1):198-208. doi:10.1542/ peds.2008-1349

20. Elsheikh M, Dunger DB, Conway GS, Wass JA. Turner's syndrome in adulthood. Endocr Rev (2002) 23(1):120-40. doi:10.1210/edrv.23.1.0457

21. Stochholm K, Juul S, Juel K, Naeraa RW, Gravholt CH. Prevalence, incidence, diagnostic delay, and mortality in Turner syndrome. J Clin Endocrinol Metab (2006) 91(10):3897-902. doi:10.1210/jc.2006-0558

22. Donaldson MDC, Gault EJ, Tan KW, Dunger DB. Optimizing management in Turner syndrome: from infancy to adult transfer. Arch Dis Child (2006) 91(6):513-20. doi:10.1136/adc.2003.035907

23. Davenport ML. Approach to the patient with Turner syndrome. JClin Endocrinol Metab (2010) 95(4):1487-95. doi:10.1210/jc.2009-0926

24. Cicognani A, Mazzanti L, Tassinari D, Pellacani A, Forabosco A, Landi L, et al. Differences in carbohydrate tolerance in Turner syndrome depending on age and karyotype. Eur J Pediatr (1988) 148(1):64-8. doi:10.1007/ BF00441818

25. Ross JL, Feuillan P, Long LM, Kowal K, Kushner H, Cutler GB Jr. Lipid abnormalities in Turner syndrome. J Pediatr (1995) 126(2):242-5. doi:10.1016/ S0022-3476(95)70551-1

26. Nathwani NC, Unwin R, Brook CG, Hindmarsh PC. Blood pressure and Turner syndrome. Clin Endocrinol (Oxf) (2000) 52(3):363-70. doi:10.1046/j. 1365-2265.2000.00960.x

27. Los E, Quezada E, Chen Z, Lapidus J, Silberbach M. Pilot study of blood pressure in girls with Turner syndrome: an awareness gap, clinical associations, and new hypotheses. Hypertension (2016) 68(1):133-6. doi:10.1161/ HYPERTENSIONAHA.115.07065

28. El-Mansoury M, Barrenäs ML, Bryman I, Hanson C, Larsson C, Wilhelmsen L, et al. Chromosomal mosaicism mitigates stigmata and cardiovascular risk factors in Turner syndrome. Clin Endocrinol (Oxf) (2007) 66(5):744-51. doi:10.1111/j.1365-2265.2007.02807.x

29. Bakalov VK, Cheng C, Zhou J, Bondy CA. X-chromosome gene dosage and the risk of diabetes in Turner syndrome. J Clin Endocrinol Metab (2009) 94(9):3289-96. doi:10.1210/jc.2009-0384
30. Irzyniec TJ, Jeż W. The influence of hormonal replacement and growth hormone treatment on the lipids in Turner syndrome. Gynecol Endocrinol (2014) 30(3):250-243. doi:10.3109/09513590.2013.872236

31. Sagi L, Zuckerman-Levin N, Gawlik A, Ghizzoni L, Buyukgebiz A, Rakover Y, et al. Clinical significance of the parental origin of the $\mathrm{X}$ chromosome in turner syndrome. J Clin Endocrinol Metab (2007) 92(3):846-52. doi:10.1210/ jc.2006-0158

32. Zuckerman-Levin N, Zinder O, Greenberg A, Levin M, Jacob G, Hochberg Z. Physiological and catecholamine response to sympathetic stimulation in turner syndrome. Clin Endocrinol (2006) 64:410-5. doi:10.1111/j.1365-2265. 2006.02483.x

33. Guo SS, Roche AF, Chumlea WC, Gardner JD, Siervogel RM. The predictive value of childhood body mass index values for overweight at age $35 \mathrm{y}$. Am J Clin Nutr (1994) 59(4):810-9. doi:10.1093/ajcn/59.4.810

34. Rongen-Westerlaken C, Corel L, van den Broeck J, Massa G, Karlberg J. Reference values for height, height velocity and weight in Turner's syndrome. Acta Paediatr (1997) 86(9):937-42. doi:10.1111/j.1651-2227.1997.tb15174.x

35. Blackett PR, Rundle AC, Frane J, Blethen SL. Body mass index (BMI) in Turner syndrome before and during growth hormone $(\mathrm{GH})$ therapy. Int J Obes Relat Metab Disord (2000) 24(2):232-5. doi:10.1038/sj.ijo.0801119

36. Reinehr T, Lindberg A, Toschke C, Cara J, Chrysis D, Camacho-Hübner C. Weight gain in Turner syndrome: association to puberty induction? Longitudinal analysis of KIGS data. Clin Endocrinol (Oxf) (2016) 85(1):85-91. doi:10.1111/cen.13044

37. Mauras N, Shulman D, Hsiang HY, Balagopal P, Welch S. Metabolic effects of oral versus transdermal estrogen in growth hormone-treated girls with turner syndrome. JClin Endocrinol Metab (2007) 92(11):4154-60. doi:10.1210/ jc.2007-0671

38. Torres-Santiago L, Mericq V, Taboada M, Unanue N, Klein KO, Singh R, et al Metabolic effects of oral versus transdermal $17 \beta$-estradiol $\left(\mathrm{E}_{2}\right)$ : a randomized clinical trial in girls with Turner syndrome. J Clin Endocrinol Metab (2013) 98(7):2716-24. doi:10.1210/jc.2012-4243

39. Reinehr T, Lindberg A, Koltowska-Häggström M, Ranke M. Is growth hormone treatment in children associated with weight gain? Longitudinal analysis of KIGS data. Clin Endocrinol (Oxf) (2014) 81(5):721-6. doi:10.1111/ cen. 12464

Conflict of Interest Statement: All authors declare that there is no conflict of interest that could be perceived as prejudicing the impartiality of the research reported.

Copyright (c) 2018 Lebenthal, Levy, Sofrin-Drucker, Nagelberg, Weintrob, Shalitin, de Vries, Tenenbaum, Phillip and Lazar. This is an open-access article distributed under the terms of the Creative Commons Attribution License (CC BY). The use, distribution or reproduction in other forums is permitted, provided the original author(s) and the copyright owner are credited and that the original publication in this journal is cited, in accordance with accepted academic practice. No use, distribution or reproduction is permitted which does not comply with these terms. 